Group-level and intraindividual stability of national stereotypes : pÿa four-year longitudinal study on Ingrian Finn immigrants pre-and postmigration stereotypes of a typical Finn

\title{
Lönnqvist, Jan-Erik
}

2013

Lönnqvist , J-E , Jasinskaja-Lahti , I \& Verkasalo , M 2013 , ' Group-level and intraindividual pÿstability of national stereotypes : a four-year longitudinal study on Ingrian Finn immigrants pre-and postmigration stereotypes of a typical Finn ', Journal of Cross-Cultural Psychology , vol. 44 , no. 5 , pp. 765-785 . https://doi.org/10.1177/0022022112466592

http://hdl.handle.net/10138/234350

https://doi.org/10.1177/0022022112466592

acceptedVersion

Downloaded from Helda, University of Helsinki institutional repository.

This is an electronic reprint of the original article.

This reprint may differ from the original in pagination and typographic detail.

Please cite the original version. 

Psychology, 44(5), 765-785.

Running Head: Group-Level and Intraindividual Stability

WORD COUNT: 8814 (body text)

Group-level and intraindividual stability of national stereotypes - a four-year longitudinal study on Ingrian Finn immigrants' pre-and post-migration stereotypes of a typical Finn

Jan-Erik Lönnqvist

Institute of Behavioural Sciences, University of Helsinki, Finland

Inga Jasinskaja-Lahti

Department of Social Research, University of Helsinki, Finland

Markku Verkasalo

Institute of Behavioural Sciences, University of Helsinki, Finland

Author Notes:

This research was supported by the Academy of Finland Research Grants 127641 and 123297. We would like to thank Antti Hulsi (Institute of Behavioural Sciences, University of Helsinki, Finland), Kaisa Kanerva (Institute of Behavioural Sciences, University of Helsinki, Finland), Tamara Kinunen (St’ Petersburg State University, Russia), Michail Vinokurov (State University of Petrozavodsk, Russia), as well as Elina Leinonen and Jesse Haapoja (Department of Social Psychology, University of Helsinki, Finland) for their help in data collection and coding. Correspondence concerning this paper should be sent to Jan-Erik Lönnqvist, Department of Psychology, University of Helsinki, PO BOX 9, 00014 University of Helsinki, Finland.

Keywords: National stereotypes, Intergroup contact, Migration, Values 
Group-level and intraindividual stability of national stereotypes - a four-year longitudinal study on Ingrian Finn immigrants' pre-and post-migration stereotypes of a typical Finn

\begin{abstract}
In a four-year longitudinal study, we investigated stereotype change in the context of increased intergroup contact. Specifically, using one pre- and two post-migration measurement points, we followed some two hundred Ingrian Finns and their families migrating from Russia to Finland. Stereotypes of a typical Finn were conceptualized within the framework provided by Schwartz' (1992) values theory. At the group level, migrants' stereotype profiles were consensual, similar to Finns' auto-stereotypes, somewhat accurate, and highly stable. However, mean-level changes indicated a process of disillusionment: Finns were increasingly perceived as less Benevolent and more Hedonistic. We argue that personal contact changes aspects of stereotypes related to communal characteristics, whereas contact with cultural institutions influences perceptions of conservativeness. Probably due to political climate, Finns were increasingly perceived as adhering to Tradition and Security values over Stimulation. Although individual-level stereotypes were only moderately stable and stereotype change was heterogeneous, we could not predict individual-level changes.
\end{abstract}


Group-level and intraindividual stability of national stereotypes - a four-year longitudinal study on Ingrian Finn immigrants' pre-and post-migration stereotypes of a typical Finn

\section{Introduction}

From Herodotus' $5^{\text {th }}$ century B.C.E. depiction of Egyptians as the wisest people of all mankind to Hollywood's contemporary portrayal of the bad Arab, national stereotypes beliefs about the characteristics of people from different countries - have fascinated scientists and laypeople alike. It could therefore be considered surprising how little is actually known about the processes through which national stereotypes are formed. Yet, such knowledge could in today's shrinking world be of considerable importance. The present study asks, in a migration setting, how increased contact affects national stereotypes. This could shed some light on the mechanisms through which national stereotypes are formed.

The present four-year longitudinal study investigated how Ingrian Finn and Russian migrants' pre-migration stereotypes of native Finnish host nationals changed post-migration. Stereotype change was investigated both at the level of the group and at the level of the individual. We were interested both in the content of the stereotype and the consensus with which it was held.

\section{Stability and Change in Group-Level National Stereotypes}

On the level of the group; that is, aggregated across individuals, the content of national stereotypes has been reported to be highly stable. Most important in this respect is a series of studies concerning the ethnic and national stereotypes of Princeton University students (Katz \& Braly, 1933; Gilbert, 1951; Karlins, Coffman, \& Walters, 1969; Madon et al., 2001), the results of which can perhaps best be summarized as suggesting that the content of stereotypes does change, but that this happens very slowly, taking decades. Regarding shorter periods of time, ranging from a couple of weeks to five years, the content of group-level stereotypes has been shown to be highly stable (e.g., Garcia-Marques, Santos, \& Mackie, 2006; Rothbart \& John, 1993; Realo et al., 2009). Also testifying to the stability of national stereotypes, they 
are strongly affected by relatively stable factors such as climatic warmth and national prosperity (McCrae, Terraciano, McCrae, \& Allik, 2007), whereas more short-term factors, such as government policies, appear to have only little impact (Terraciano \& McCrae, 2007).

National stereotypes have not previously been investigated in a migration context. Examining the stability of national stereotypes in such a context of heightened intergroup contact could help illuminate some of the processes through which national stereotypes are formed. The migration context should be especially well suited for investigating the kernel of truth hypothesis (e.g., Allport, 1978/1954; Brigham, 1971), which suggests that national stereotypes are to some extent accurate, reflecting real differences between people. If this is correct, then increased contact should lead to increased accuracy. Despite the plausibility of the kernel of truth hypothesis, it has been challenged by some recent empirical results. Terracciano et al. (2005) had respondents from 49 countries provide self-ratings of personality and rate the personality of a typical member of their cultural group. Comparison of these two sets of ratings revealed that stereotypes did not correspond with average selfratings. One reason for this could be that people generally have little experience with other cultures, and may therefore lack a reference point for rating their own culture (Robins, 2005). A related possibility is that auto-stereotypes (stereotypes of one's own nation) are erroneous, but hetero-stereotypes (stereotypes of other nations) are more truthful (Robins, 2005). Taking a different approach to studying the accuracy of national stereotypes, Church and Katigbak (2002) asked Americans and Filipinos who had lived in both America and the Philippines for at least three years to judge the personality traits of Filipinos and Americans. These ratings were not correlated with average self-ratings of personality obtained from American and Filipino samples.

Challenging the above results according to which national stereotypes are not accurate, a seven country study by Realo et al. (2009) showed that when the same measurement instrument was used to assess both personality and national character stereotype, relatively good agreement between self-ratings and auto-stereotypes was found. 
Such agreement was also reported for Ingrian Finn and Russian potential migrants' premigration stereotypes regarding the personal values of a typical Finnish host national (Lönnqvist, Yijälä, Jasinskaja-Lahti, \& Verkasalo, 2012). The present research design, in which we longitudinally monitor these same migrants throughout the migration process, should be ideal for investigating the kernel of truth hypothesis.

Increased first-hand experience with a country and its residents could also have other effects than increased accuracy. Hetero-stereotypes of Americans (Terraciano \& McCrae, 2007) and Russians (Realo et al., 2009) have been shown to converge with auto-stereotypes. Direct contact could lead to increased knowledge of the auto-stereotype, and the heterostereotype could thus be expected to become more similar to the auto-stereotype.

There may also be migration specific effects on national stereotypes. Based on previous results, one could expect stereotypes to become either more or less positive. Migration will necessarily involve increased intergroup contact, and if satisfactory, this contact could lead to increased favourability towards the outgroup (for a meta-analysis, see Pettigrew \& Tropp, 2006). However, the opposite effect could be expected if the postmigration contact is negative or discriminatory. Typically, the contact hypothesis literature conceives of intergroup contact as general contact evaluated, e.g., for its pleasantness or superficiality. But intergroup contact may for migrants also involve experiences of outgroup rejection and ethnic discrimination. For example, our recent studies conducted with the same sample of participants have shown that immigrants who, after migration, perceived more negative intergroup contact than they had expected, were more likely to disidentify from the national majority group and to increasingly show negative attitudes towards this group (Jasinskaja-Lahti \& Mähönen in press; Jasinskaja-Lahti, Mähönen, \& Ketokivi, 2012; Jasinskaja-Lahti, Mähönen, \& Liebkind, in press). Similarly, a study on Jewish adolescents from Russia and Ukraine participating in an Israeli immigration program showed that premigration idealization of the receiving country was typically replaced by post-migration 
disillusionment (Tartakovsky, 2009a). The stereotypes of host nationals could thus become more negative post-migration.

Besides content, another important aspect of national stereotypes is the extent to which they are consensual (i.e., the extent to which people agree on which characteristics describe a group). In general, the more consensual stereotypes are, the more often those stereotypes will be confronted, and the more they will thereby shape the behavior of the stereotyped group (e.g., Chen \& Bargh, 1997). The above mentioned Princeton trilogy and its follow-ups have provided mixed evidence regarding the long-term stability of stereotype consensus, with some studies suggesting decreased (Devine \& Elliot, 1995; Dovidio \& Gaertner, 1986) and others increased (Madon et al., 2001) consensus. Similarly, regarding the effect of increased intergroup contact on stereotype consensus, the empirical evidence does not allow for any straightforward conclusions. Some studies have shown consensus to decrease with increased familiarity with the stereotyped group (e.g., Katz \& Schank, 1938), but others have uncovered the opposite pattern (e.g., Schoenfeld, 1942).

\section{Stability and Change at the Level of the Individual}

There are extremely few studies on the intraindividual stability of stereotypes. One unpublished study, described by Rothbart and John (1993), showed that although the grouplevel stability of ethnic stereotypes was, across a four-year interval, extremely high, the individual-level stability of stereotypes was only moderate. Another study showed a similar pattern of results, with extremely high group-level stability, but only moderate intraindividual stability over a time period of a couple of weeks (Garcia-Marques et al, 2006).

Examining stereotype change at the intraindividual level could in several ways contribute to our understanding regarding the processes that influence stereotypes. First, intraindividual analysis allows for the examination of how similar the process of stereotype change is across individuals. Due to lack of empirical research, very little is known about the extent to which stereotype change is consensual. However, this type of knowledge could be vital, as it directly speaks to the extent to which stereotype change is influenced by common 
experiences: the more consensual stereotype change is, the more likely it is to be influenced by common experiences of societal and institutionalized forces, such as television programs, newspapers, books, films, and political leaders. In the present context, the question is whether the migration process has a uniform impact on stereotypes, or whether some migrants' stereotypes change in one way and others' in some other way.

Related to the above, if the process of stereotype change is not uniform across individuals, it could be meaningful to examine the associations of stereotype change with other individual-level variables. Because migrants' experiences of intergroup contact are likely to vary between individuals, the intergroup contact hypothesis described above could also find support at this level of analysis: Increased quantity and especially good quality of interaction with native Finns could render the stereotype of Finns more positive. By contrast, experiences of discrimination could have the opposite effect. Also the disillusionment process, described above at the level of the group, could be expected to be found at the level of the individual - those with more positive pre-migration feelings towards Finns could experience more profound post-migration changes in their stereotype of Finns. On the other hand, such migrants may have experienced more pre-migration contact with Finns, rendering their stereotypes less susceptible to change.

\section{Purpose of the Present Research}

The present study is part of larger longitudinal research project (Intervening at the premigration stage: Providing tools for promoting integration and adaptation throughout the migration process; INPRES) that followed a sample of Ingrian Finns and their families in the context of migration from Russia to Finland.

National stereotypes were measured within the framework provided by Schwartz' (1992) theory on personal values. Values are concepts or beliefs that act as standards of what is most desirable in the appraisal of events, actions, and people. Values diverge from attitudes in that they transcend particular situations, are organized within an individual according to 
importance, establish criterions of desirability, and are fewer and more crucial to personality than are attitudes.

Due to the scarcity of previous longitudinal research on stereotype change, the complete lack of such research in a context of increased intergroup contact, and the often inconsistent findings reviewed above, exact predictions were difficult to make. However, we did expect stereotypes to be relatively stable at the level of the group, but individuals to show much less stability (Garcia-Marques et al, 2006; Rothbart \& John, 1993). Regarding the content of stereotypes, during the migration process, Ingrian Finns' and Russians' stereotypes of Finns could, as a result of increased contact, be expected to become more accurate (supporting the kernel of truth hypothesis; Realo et al., 2009; cf. Church \& Katigbak. 2002; Terraciano et al., 2005), but also to become more similar to the auto-stereotypes of Finns (Realo et al., 2009; Terraciano et al., 2005). Regarding the latter, these were, in the present study, measured in a sample of Finnish students - previous research suggests students' national stereotypes to be generalizable to the whole population (Terraciano et al., 2005). Based on the contact hypothesis (Pettigrew \& Tropp, 2006), the content of migrants' stereotype of Finns could be expected to become more positive. However, the opposite could also be true, as migrants may during the post-migration phase become disillusioned with their host country (Tartakovsky, 2009a).

Another set of questions relates to consensus. How consensual are stereotypes, and how consensual is stereotype change over time? Regarding the former question, previous findings are very mixed (e.g., Katz \& Schank, 1938; Schoenfeld, 1942), and there is no research on the latter question. This forced a rather exploratory approach to these questions.

It seems plausible to expect that individuals' stereotypes may change in different ways, and that such individual differences could be predictable. Those with more premigration experience of Finland could already have a rather stable stereotype, less susceptible to change. Furthermore, their pre-migration stereotype could be more positive (Pettigrew \& Tropp, 2006). In our previous studies, utilizing the pre-migration data of the INPRES project, 
the more positive the pre-migration contact of potential migrants with Finnish host nationals, the more positive were their attitudes toward Finns and the less they anticipated discrimination and adaptation problems after migration (Jasinskaja-Lahti \& Yijälä, 2011; Yijälä \& Jasinskaja-Lahti, 2010). However, as stated earlier, these positive experiences and expectations could also render them more vulnerable to post-migration disillusionment (Jasinskaja-Lahti et al., in press; Jasinskaja-Lahti et al., 2012; Jasinskaja-Lahti \& Mähönen, in press; Tartakovsky, 2009a; 2009b). Importantly, not all intergroup contact may influence stereotypes similarly: satisfactory contact was expected to be associated with increased favourability towards the national majority group (Pettigrew \& Tropp, 2006), but the opposite effect was expected when post-migration contact had been experienced as discriminatory.

Regarding methodology, we decided to analyse the Ingrian Finn migrants (so called primary applicants of Finnish descent) and their family members (spouses of mostly Russian ethnicity), as separate samples, as the two groups could have been expected to differ in some respects (e.g., the Ingrian Finns could have experienced more contact with Finns prior to migration). This methodological decision also served to keep all observations independent.

\section{Method}

\section{Participants and Procedure}

Finnish students. Auto-stereotypes of Finns were measured in a sample of 38 Finnish students ( 8 males; mean age $=34.8$ (range $21-58), S D=11.1)$ taking part in an introductory course in psychology arranged by the University of Helsinki. Participants rated online the values of a typical Finn. The course was an Open University course (anyone can attend these courses), and therefore the mean age was somewhat higher than in more typical student samples, arguably contributing to the representativeness of the sample. The low number of males in our sample may raise some concerns; however, mean male and female stereotype profiles were virtually identical ( $r=.96$; independent samples $t$-tests for equality in means also revealed no differences between males and females, for all ten values, $t<1.8, p>.05$ ). 
The ratings were collected in the summer of 2011, at around the same time that most of the migrants completed the second follow-up.

Emigrating Ingrian Finns and Russians. Ingrian Finns and Russians were participants of the INPRES project investigating the migration of Ingrian Finns and their family members to Finland between 2008 and 2011. The Ingrian Finns are mostly offsprings of Finnish colonizers who settled down in Ingria (now Leningrad Oblast) in the 17th century. After the Russian conquest in 1703 many remigrated back to Finland. Of those who remained, many went missing in the forced population transfers before and after WWII, and many migrated to Finland soon after the breakdown of the Soviet Union in the first years of the 1990s. However, there are still about 30,000 Ingrian Finns remaining in Russia. After completing an official language test, Ingrian Finns are qualified for guaranteed habitation permit in the Finnish Law of Return. The base-line sample of the project consisted altogether of 325 potential migrants living in the Republic of Karelia or the Leningrad area. We measured participants' stereotype of Finns three times, once before migration (T0) and twice postmigration (T1 and T2). Pre-migration experience of Finland and attitude towards Finns were measured at T0, and experienced intergroup contact at T2.

The T0 data was collected at the Finnish language courses that were part of the immigration training program organized by the Finnish authorities in Russia during April and May 2008. Everyone attending these courses $(N=192)$ completed the questionnaires in class. The language students were instructed to take home an additional questionnaire to be completed by family members (spouses) joining the respondent in Finland $(N=84)$. In addition, the questionnaire was mailed to those potential migrants who had already passed the mandatory language test and were waiting to be assigned a particular place of residence in Finland $(N=49)$. These participants were identified via the register of the Finnish Consulate in Russia (St. Petersburg) and they participated via post survey. The mean age of the participants at T0 was 43.1 years $(S D=14.4$ years) ranging between 19 and 85 years. Most participants were married or cohabiting (70\%) and had children (77\%). Further, most of 
them had full-time employment (61\%), while only three per cent were unemployed or temporarily dismissed at T0. Every second (46\%) of these 325 participants thought that they would be able to migrate within the following seven or eight months.

As the participants of the base-line study migrated to Finland according to their personal schedules, the follow-up data could not be collected at once. Instead, for the first post-migration assessment (T1), three searches from the Finnish population register were performed between October 2009 and December 2010 in order to include as many base-line participants as possible. Each round consisted of an initial request to participate, including the post-migration questionnaires and a return envelope, followed by two reminders. The participants were identified by their name and date of birth. At the end of the third search, a total of 233 respondents (70\%) of our baseline sample had migrated to Finland by December 2010, of whom 227 respondents took part in the study at T1.The mean age in the T1 followup sample was 44.3 years $(S D=13.9)$. Most participants were females $(63 \%)$, and they were still married or cohabiting (69\%). Despite their high level of education prior to migration (only $15 \%$ had no education beyond secondary school), they had not yet been employed in Finland, but were typically unemployed (49\%), on pension (10\%) or studying (12\%) at T1.

The second follow-up (T2) was conducted 12-20 months after T1 assessment, using the same procedure as described above. In total, 194 (82\% of all T0 participants that had migrated to Finland by December 2011, and $86 \%$ of T1 participants) migrants participated at T2. The mean age in the second follow-up sample was 45.4 years $(S D=13.4)$. Most participants were females (63\%), were typically still married or cohabiting (62\%) and typically still unemployed (49\%), on pension (8\%) or studying (19\%).

In order to examine possible selection bias due to sample attrition, $t$-tests on relevant demographic factors (gender, age, marital status, socioeconomic status, employment status, level of education, Finnish language proficiency) and other T0 variables used in this study were performed. Our final sample did not differ in terms of socio-demographic factors or in terms of their responses to $\mathrm{T} 0$ scales from those respondents participating only at $\mathrm{T} 0$. 
For the here presented analyses, we included only participants who took part at all three measurement occasions; that is, 136 ethnic migrants (Ingrian Finns; 37 males, mean age at $\mathrm{T} 0=44.4, S D=14.1)$ and their 56 spouses (46 Russians and ten participants of other ethnic origin from within the former Soviet region; 34 males, mean age $=40.6, S D=11.1$ ). We refer to these two groups of migrants as Ingrian Finns and Russians, respectively.

The migrants had arrived in Finland between 3 and 15 months (Ingrian Finns: $M=9.6$ months, $S D=3.9$; Russians: $M=10.5$ months, $S D=3.8$ ) before the $\mathrm{T} 1$ assessment, and between 13 and 28 months before the T2 assessment (Ingrian Finns: $M=22.0$ months, $S D=$ 4.1; Russians: $M=23.0$ months, $S D=3.9$ ). In both samples, the average time that had elapsed between T0 and T1 was 19 months, and the average time between T1 and T2 was 12 months.

Representative Sample of Finns. As a criterion for the accuracy of stereotypes of Finns, we used self-rating of values. These were gathered from strict probability samples, representative of the population 15 years and older, in the third round of the European Social Survey (ESS; Jowell et al., 2007). Finland had 1646 (782 males; mean age 48.2, SD = 18.6) participants. The data was collected in the fall of 2006.

\section{Measures}

Portraits Values Questionnaire. At the level of the individual, people in most cultures (recently 77; Schwartz, 2009) distinguish between at least ten basic values. Schwartz (1992) has labeled these universal value types as: Benevolence, Tradition, Conformity, Security, Power, Achievement, Hedonism, Stimulation, Self-Direction, and Universalism. Our measure of the ten basic values was the 21-item Portrait Values Questionnaire (PVQ21). It is based on descriptions of different people, whose goals, aspirations and wishes are characterized in two sentences (Davidov, Schmith, \& Schwartz, 2008). For example, the item "It is important to her to show her abilities. She wants people to admire what she does" measures Achievement values. In the ESS, respondents indicate "how much like you this person is" by using a 6point scale ranging from 1 (very much like me) to 6 (not like me at all). For the present study, 
all items were reverse scored, so that the higher the number, the stronger the agreement with the item. When two values or less were missing, the missing values were replaced using the regression method. By mistake, the PVQ21 was, in the migrant samples, administered using a 5-point scale ranging from 1 (not like me at all) to 5 (like me); the response option 6 (very much like me) was left outside the printable area of the questionnaire. To facilitate comparison between samples, scores of 5 or 6 were recoded into 5 in the Finnish student sample and in the ESS data.

The average internal consistency reliability of our Finnish students' ratings of the typical Finn was, across the ten basic values, .57 (range $=.23$ (Self-Direction) to .84 (Hedonism)). In the Ingrian Finn and Russian migrant samples, the corresponding ratings showed similar and acceptable levels of internal consistency reliability (average T0/T1/T2 $\alpha$ s $=.56($ range $=.29($ Stimulation $)-.77($ Security $)) / .53($ range $=.16($ Stimulation $)$ to .71 $($ Achievement $)) / .60($ range $=.28($ Stimulation $)-.73($ Achievement $))$ and $.62($ range $=.40$ (Achievement) to .81 (Security) /.55 (range $=.40($ Tradition) to .73 (Achievement) /.61 (range $=.44$ (Power) to .79 (Conformity), respectively). Although some of the reliabilities were low, this cannot be considered very surprising, as each of the basic values, despite representing broad constructs, is measured by only two items (three for Universalism). The reliabilities are in line with the reliabilities reported in earlier studies (e.g., Schwartz, 2007; Schwartz \& Rubel, 2005), suggesting no particular problems in the current samples, or with the instructions to rate stereotypes. In fact, low alpha reliabilities may not threaten measurement validity; McCrae, Kurtz, Yamagata and Terracciano (2011) demonstrated that internal consistency reliability is not related to various validity criteria.

The PVQ21, like all other measures, was administered in the Russian language to our samples of Ingrian Finns and Russians. This may raise concerns regarding the comparability of scores on the Russian and Finnish translations of the PVQ21 (the Finnish student sample and the representative sample of Finns responded in Finnish). Indeed, the Finnish and Russian translations of the PVQ21 display configural and partial metric invariance, but not 
scalar invariance (Davidov, 2010). This allows researchers to compare the correlates of these two questionnaires across countries, but not to compare mean scores. We used the scores obtained with the Finnish translation only for purposes of computing profile correlations, not to compare mean scores. Supporting the comparability of values profiles collected with the Russian and Finnish translations of the PVQ, the average self-rating values profiles of the Ingrian Finns (not shown) and the representative sample of Finns were almost identical ( $\mathrm{r}=$ .94; for evidence that value profiles should not differ much across cultures, see Fischer, \& Schwartz, 2011).

Because some of our predictions concerned changes in the valence of the stereotype, it is important to note that some values may be more desirable than others. Across cultures and measurement instruments (Schwartz \& Bardi, 2001), the most important value tends to be Benevolence, strongly implying that it is the most socially desirable value (see Edwards, 1953). Consistent with this, at least when judging others, communal characteristics are generally considered the most desirable (Abele \& Wojciszke, 2007), and Benevolence values are highly correlated with measures of socially desirable responding, which indicates the degree to which a person strives to make a good impression (Schwartz, Verkasalo, Antonovsky, \& Sagiv, 1996, Verkasalo \& Lindeman, 1994). By contrast, Hedonism, on the opposite side of the values circle (see Figure 1, Schwartz, 1992), could be considered the least socially desirable value, as it focuses on gratification of own sensual desires. Consistent with this, Hedonism scores are negatively correlated with socially desirable responding (Schwartz et al., 1996; Verkasalo \& Lindeman, 1994).

Pre-migration experience of Finland and attitude towards Finns. Pre-migration experience of Finland was assessed with an item asking participants how often they had visited Finland. The response options were 0 (never), 1 (once or twice), 2 (3 or 4 times), 3 (5 or 6 times), 4 (7 or 8 times), and 5 (9 or more times). The item was used both as a continuous variable and as a dichotomous variable that indicated whether or not the participant had ever visited Finland prior to migration. In the sample of Ingrian Finns, the median response was 5 
or 6 previous visits to Finland, and only $12(9 \%)$ had never visited Finland. In the sample of Russians, the median response was one or two previous visits to Finland, and 14 (25\%) had never visited.

A feeling thermometer (e.g., Paolini et al., 2004; Verkuyten, 2007) was used to assess overall feeling toward Finns. Ratings were made on scale ranging from 0 (very cold or negative feelings) to 100 (very positive or warm feelings). The mean of the one-item measure was, in the sample of Ingrian Finns, $87(S D=14)$, and in the sample of Russians, $89(S D=$ $18)$.

Intergroup contact. Quantity of intergroup contact was measured with five items: participants indicated on a scale from zero (Not at all) to six (Very much) how much contact they had experienced with native Finns in each of the following contexts: at college, as neighbours, as close friend, as authorities, and as employers/teachers. The first three items were from a scale developed by Islam and Hewstone (1993), to which we added the last two items. In the sample of Ingrian Finns/Russians the descriptive statistics were $M=2.83, S D=$ $1.31, \alpha=.68 / M=2.74, S D=1.30, \alpha=.68$.

Quality of contact was measured by having participants rate each of the above five contexts on three items. Specifically, on a scale from one (Not at all) to five (Very), participants responded to the item "'When you meet native Finns, in general do you find the contact ...' followed by three adjectives: pleasant, cooperative, and superficial (the last one was reverse-coded). The descriptives of this fifteen-item scale, adapted from a study by Voci and Hewstone (2003), were, in the sample of Ingrian Finns/Russians, $M=3.53, S D=0.79$, $\alpha$ $=.78 / M=3.49, S D=0.68, \alpha=.89$.

To assess more negative experiences of intergroup contact, we measured perceived discrimination using four items: "I think native Finns do not accept me because I come from Russia", "I think native Finns have something against me because I come from Russia", "Native Finns have harassed me or insulted me because I come from Russia", and "Native Finns have threatened me or attacked me because I come from Russia". The items, adapted 
from the discrimination scale by Berry, Phinney, Sam, and Vedder (2006), were rated on a scale from one (completely disagree) to five (completely agree). In the sample of Ingrian Finns/Russians the descriptive statistics were $M=1.96, S D=0.77, \alpha=.77 / M=2.03, S D=$ $0.67, \alpha=.65$.

\section{Results}

The means and standard deviations of the personal values of a representative sample of Finns are shown in Table 1. These statistics are also shown for Finns' stereotype of Finns, as well as Ingrian Finn and Russian migrants' stereotypes of a typical Finn at the three measurement points.

\section{Group-Level Results}

Before examining the ten basic values individually, we combined information over all ten values by conducting analyses using the values profiles that the ten basic values constitute. We first examined whether there within the different samples existed a shared stereotype of Finns, and whether this stereotype, within the groups of migrants, became more or less consensual over time. Intra-class correlation coefficients (ICCs) were used to assess interrater consensus. All ICCs reported on are from two-way mixed effects models: Both objects (the ten basic values) and raters contributed systematic variability, and rater effects were fixed (raters did not constitute a random sample drawn from a larger population). The singlemeasures ICCs indicate the percentage of shared variance between any two raters' stereotype profiles. The average measures ICCs show the variance that the average profile would be expected to share with an average profile derived from a similar sample of raters. The ICCs shown in Table 2 indicate that within all groups, participants shared a rather similar stereotype of the values of a typical Finn. Furthermore, the highly over-lapping confidence intervals suggest that there were no differences in consensus, either between groups of participants or over time.

We next examined the group level accuracy and stability of stereotype profiles. This was done by correlating amongst each other the actual personal values of the representative 
sample of Finn (ESS sample), and Finns', Ingrian Finns' and Russians' stereotypes of the typical Finn. For such correlational profile analyses, using Schwartz' (1992) values theory as a general framework provides two advantages: the direction of keying is meaningful (an arbitrary direction of keying would influence indices of profile similarity; Tellegen, 1965), and only the shape of the profiles matters (differences in elevation present response bias and should be ignored; Schwartz, 1992). These considerations make Pearson's correlation coefficient, shown in Table 3, an appropriate statistic. There are five important things to notice about these correlations. (a) Ingrian Finns' and Russians' ratings of the typical Finn were, across measurement points, rather accurate, whereas Finns' ratings were not. (b) Both Ingrian Finns' and Russians' stereotypes, besides being rather accurate, resembled Finns' auto-stereotype. In fact, Finns' self-ratings (ESS sample) and Finns' auto-stereotype (student sample) both contributed to the prediction of Ingrian Finns' and Russians' hetero-stereotypes of the typical Finn. For instance, in the prediction of Ingrian Finns' pre-migration stereotypes, a regression model including only Finns' self-ratings as predictor variable predicted $50 \%\left(R^{2}\right)$ of the variance $(p=.02)$, and this number increased to $80 \%(p=.005)$ when Finns' autostereotypes were added to the model (change in $R^{2}=30, p=.01$ ). Similarly, Finns' self-rating could predict Ingrian Finns' hetero-stereotypes beyond that which was predicted by Finns' auto-stereotypes $\left(R^{2}\right.$ increased from $.68(p=.003)$ to $.80(p=.005)$, change in $R^{2}=12, p=$ .08 ), although the effect did not quite reach statistical significance. Virtually identical results were obtained for all three measurement points and in the sample of Russians. (c) Both Ingrian Finns' and Russians' stereotypes remained remarkably consistent over time, with all profile-profile correlations across the three measurement points exceeding .97. (d) Neither Ingrian Finns' nor Russians' stereotypes became more accurate over time (first column of Table 3), (e) nor did they become more similar to Finns' auto-stereotype (second column of Table 3).

To assess mean-level changes in the content of Ingrian Finns' and Russians' stereotypes, we evaluated the data with a repeated measures regression analysis (see 
Misangyi, LePine, Algina, \& Goeddeke, 2006). The repeated measures regression procedure fit, for each migrant, a regression line to his three ratings over time. Specifically, one basic value at a time, each migrant's stereotype was predicted by the time intervals of zero (corresponding to years lived in Finland at T0), years in Finland at first follow-up, and years in Finland at second follow-up. This procedure derived for each migrant an intercept value, which indicated how the migrant on average rated Finns, and a slope value, which indicated how the migrant's ratings changed as a function of time. Furthermore, we also included, in the same regression, the curvi-linear effects of time, because some changes could conceivable be only temporary. The average intercepts and slopes are shown in Table 4 . These reveal that on average, Ingrian Finns' perceptions of the typical Finn became less positive over time, with a decrease in perceived Benevolence, and an increase in perceived Hedonism. Furthermore, Ingrian Finns also perceived Finns as increasingly conservative (Tradition and Security up, Stimulation down). Almost identical results were obtained in the sample of Russians, but these tended not to be statistically significant due to smaller sample size. Curvilinear effects were neglectable.

\section{Individual-Level Results}

The above group-level analyses revealed high stereotype profile stability across time. We next investigated whether such high profile stability could also be found at the level of the individual. At this level of, we were able to differentiate between overall similarity and distinctive similarity. As noted by Cronbach (1955), there are two components that influence similarities in profile shape: stereotype accuracy and differential accuracy. Stereotype accuracy refers to the similarities that any two profiles will share. Applied to the present case, the Ingrian Finns clearly shared a stereotype regarding the values profile of a typical Finn. This means that any two randomly chosen Ingrian Finns' stereotypes of the typical Finn will, even across time, be somewhat similar. If one is interested in the stability of an individual's stereotype profile, then such similarity between random profiles will inflate stability estimates. Therefore, one should instead look at distinctive similarity, which controls for the 
shared variance of all profiles. In cross-cultural data, this means standardizing the data using cross-cultural norms (Terracciano et al., 2005). In individual-level data, this means computing the indices of profile similarity from data first standardized across individuals. The resulting index of profile similarity indicates how the pattern of how a profile (specific individual's T0 stereotype) deviates from other profiles (average of other individuals' T0 stereotypes) reflects how another profile (specific individual's T1 stereotype) deviates from other profiles (average of other individuals' T1 stereotypes). Both overall and distinctive profile similarity coefficients (Pearson's $r$ ) are presented in Table 5 (we used the Fisher $r$-to$Z$-to- $r$ averaging procedure). The psychometrically preferable distinctive similarity coefficients indicated, as expected, that stereotype profiles were only moderately stable at the level of the individual.

The rank-order stabilities (test-retest correlations) of specific values are given in Table 6. Consistent with the only moderate stability of the individual-level values profiles, the rank-order stabilities of some of the basic values were not very high. This means that migrants changed their relative ordering compared to other migrants; e.g., the same migrants who pre-migration perceived the Finns as more Benevolent than did other migrants, did not necessarily do so post-migration.

To assess whether changes in the stereotype were consistent across individuals (was it the same people whose perceptions of Finns' Benevolence and Stimulation decreased, and whose perceptions of Finns' Hedonism, Security and Tradition increased), we computed the ICC for value change. This analysis was based on the ten Beta values (one Beta estimate for each of the basic values) that each individual obtained in the within-individual regression analyses. The obtained ICC revealed that any two random Ingrian Finn migrants' value change profiles shared zero percentage of their variance $(p=.79)$. A similar result was obtained in the sample of Russian migrants $(p=.81)$. The migrants did thus not experience uniform changes in their stereotypes of the values profile of a typical Finn. Rather, some 
migrants' stereotypes changed regarding some values, and other migrants' regarding some other values.

\section{Predictors of Stereotype Change}

The above results suggest that stereotypes were only moderately stable at the level of the individual, and that there was no uniform pattern to how stereotypes changed. Such circumstances could have been expected to facilitate the search for individual-level predictors of stereotype change. Recall that we predicted that positive and negative experiences with Finns could potentially influence the stereotype of Finns. To examine this, we correlated quantity of contact with Finns, quality of contact with Finns, and perceived discrimination by Finns with the slopes obtained from the within-participants regression analyses. None of the resulting 30 correlations reached conventional levels of statistical significance (in both samples, all $p>.05)$. To assess the overall magnitude of stereotype change, we created for each individual a sum score by adding up the absolute values of the individual's slope coefficients (derived from the within-individual regression), but this index was also not correlated with the three variables reflecting direct experience with Finns (in both samples, all $p>.05)$.

Finally, we did not find evidence that those migrant with more frequent pre-migration contact (coded either as a continuous or dichotomous variable) would have had a different initial stereotype (indexed by the intercepts from the within-participant regressions): across both samples, only one correlation out of the 40 (ten basic values $\mathrm{x}$ two indices of contact $\mathrm{x}$ two samples) tested reached statistical significance. The same result was found when examining stereotype change (as indexed by the betas from within-participants regressions): one correlation (out of 40) was statistically significant. Regarding the predictive power of pre-migration positive feelings, scores on the thermometer scale were not correlated with any of the intercept values from within-participants regression analyses, and with only one (out of 20 (ten slopes $\mathrm{x}$ two samples)) of the beta values. Furthermore, neither pre-migration contact nor feelings towards Finns predicted the overall magnitude of stereotype change. 


\section{Discussion}

The data presented here force us to acknowledge that there are no simple answers to questions regarding stability and change in stereotypes. In the present context, the extent of stability and change in migrants' stereotypes depended on whether one examined (a) the group or the individual, (b) profile scores that combined information over all ten basic values or single basic values, and (c) the rank-order or absolute stability of single values. Based on our results, we argue that the specific mechanisms involved in stereotype change may be different for different aspects of the stereotype.

\section{Mechanisms of Stereotype Change}

We initially suspected that migrants' stereotypes could become more accurate or more similar to Finns' auto-stereotypes as a result of increased intergroup contact. However, group-level profile scores were extremely stable. This could be because the pre-migration stereotypes were already (a) rather accurate, as shown by comparison with self-ratings from a representative sample of Finns, and also (b) similar to Finns' auto-stereotype. In fact, around $80 \%$ of the variance of pre-migration stereotypes could be explained by correspondence with Finns' self-ratings and Finns' auto-stereotype. Upon increased contact with Finns, and thereby also increased knowledge of Finns' auto-stereotype, migrants most likely found support for both those aspects of their stereotype that corresponded with Finns' self-ratings, as well as those aspects that corresponded with Finns' auto-stereotype (for confirmatory biases in information processing, see Lord, Ross, \& Lepper, 1979; Kunda, \& Oleson, 1995).

Apart from the above longitudinal perspective, it is worthwhile to note that the results support the idea that hetero-stereotypes may, among well-informed individuals, be more accurate than auto-stereotypes, for instance due to the availability of a reference point (Robins, 2005). However, hetero-stereotypes, despite being somewhat accurate, resembled Finns' auto-stereotypes even more than they resembled Finns' self-ratings. We also have more confidence in this latter result (as compared to the results pertaining to accuracy), as it 
is similar to previous results according to which hetero-stereotypes of the personality traits of Americans (Terraciano \& McCrae, 2007) and Russians (Realo et al., 2009) converge with auto-stereotypes. One reason for this could be that both auto-stereotypes and heterostereotypes are to some extent based on similar knowledge of facts about the target of the ratings. For instance, at least some Finns and migrants to Finland are likely to know that Finland tends to be ranked as being one of the least corrupt countries in the world (e.g., Zook, 2009) and this may be reflected in high ratings of the typical Finns' Conformity and Security values.

Although group-level stereotype profile scores were extremely stable, meaningful mean-level changes could be observed for some of the ten basic values. One clearly observable trend was that stereotypes became less desirable over time, with perceptions of native Finns' Benevolence decreasing and perceptions of their Hedonism increasing. Tartakovsky (2009a) identified a disillusionment process in his study on Jewish adolescents migrating to Israel. Consistent with the results of that study, in which the attitude towards Israel became more negative post-migration, our participants revealed an increasingly negative stereotype of Finns. In general, for increased contact to lead to increased favourability towards the outgroup, the contact should optimally be positive, equal status, and co-operative (e.g., Pettigrew \& Tropp, 2006). The contact between Ingrian Finns and native Finns has most likely not fulfilled these criteria. In fact, much of the contact is likely to have occurred in a context in which the migrant has been in a low-status position, for instance applying for jobs, educational programs, public housing, or well-fare benefits. In such unequal status contexts, high-power individuals tend to behave in a more selfish way (De Cremer \& Van Dijk, 2005), show less social engagement (Kraus \& Keltner, 2009) and interrupt others more often during interpersonal interaction (Hall, Coats, \& LeBeau, 2005). High-power individuals are also stereotypically perceived as colder and less friendly (Conway, Pizzamiglio, \& Mount, 1996). The results of our previous studies on the quality of intergroup contact and anticipated and perceived discrimination, conducted with the same 
sample of migrants as this study (Jasinskaja-Lahti et al., in press; Jasinskaja-Lahti et al., 2012; Jasinskaja-Lahti \& Mähönen, in press), also suggest that the intergroup contact experienced by our participants had not been positive - Immigrants have reported less positive contact and more discrimination after migration than they have anticipated premigration.

The stressfulness of the acculturation experience could also in part be responsible for the stereotypes of Finns becoming increasingly negative. Especially the second year after migration may be difficult, with psychological adjustment and adaptation again beginning to improve in the third year (Tartakovsky, 2009b). As our migrants had, on average, lived in Finland for only 22 months at T2, it is possible that they were still at the bottom of the suggested U-curve of adjustment. This could have had an adverse effect on their perceptions of Finns. A fourth measurement point, planned for 2013, will reveal whether stereotypes of Finns will again become more positive as migrants increasingly adapt to their new environment.

Through what mechanism did ratings of Finns' Benevolence become more negative? The rank-order stabilities of the ten basic values revealed that migrants were more likely to change their relative positions regarding some values than other values. Most unstable in this regard were ratings of Benevolence (lowest test-retest $r=.05$ ). Benevolence values also changed the most in terms of absolute stability. Migrants were thus more likely to change their ratings of Finns' Benevolence than their ratings of Finns' other values. One explanation for this could be that "perceivers first of all want to know whether another person is benevolent" (Abele \& Bruckmüller, 2011, p. 935). Research on person perception shows that people initially strive to infer another person's benevolence in order to make approach and avoidance decisions (e.g., Baumeister \& Leary, 1995), and that information related to this dimension is preferentially processed on a cognitive level (Abele \& Bruckmüller, 2011). Our migrant participants may more or less automatically have judged the benevolence of those 
Finns with whom they had been in contact, and this contact may not always have been positive, influencing the migrants' stereotypes of Finns.

Another trend that could be observed in mean level changes was that the stereotype of Finns moved in the direction of increased adherence to Conservation values (as opposed to Openness to Change values). This trend was evident in increased perceptions of adherence to Security and Tradition, and decreased perceptions of adherence to Stimulation. One of the most central themes to Conservation values is that they serve to maintain or justify the status quo. These shifts could thus also partly reflect a process of disillusionment - migrants may by Finns be perceived as threatening the traditions, conventions and norms established by the system (e.g., Huddy \& Sears, 1995), and migrants could pick up such a fearful attitude. In contrast to ratings of Benevolence, migrants kept, at least to some extent, their relative positions in their ratings of Security, Tradition, and Stimulation. That is, although migrants showed mean level shifts in their ratings of these values, these shifts were more or less common to all migrants. The factors that caused such mean level changes were therefore likely to be rather similar across migrants, perhaps including common experience of Finnish television, laws, newspapers, officials, political leaders, or other cultural institutions.

Related to the uniform changes in migrants' perceptions of Finns' adherence to Conservation values, of particular interest is that the period of migration happened to coincide with the breakthrough of the True Finns - a political party with national identity or Finnishness as its pivotal concept (Arter, 2010). During the four-year span of the present study, the national vote share of this party rose steadily from around five to twenty percent, as reflected for instance in the 2007 and 2011 parliamentary elections - the number of seats that the True Finns won rose from 5 to 39 out of 200 (Nurmi \& Nurmi, 2012). Furthermore, like other populist radical right-wing parties, the True Finns commanded disproportionately much media attention (see Mazzoleni, Stewart, \& Horsfield, 2003). Although still lacking xenophobic extremism, the mono-culturalist orientation of the True Finns - the party explicitly states that multiculturalism should not be promoted- and the espousing of a 
Christian society grounded in traditional family values (Arter, 2010), could have led migrants to increasingly view Finns as adhering to Tradition and Security values.

Regarding changes in other values then the above, no clear patterns emerged. Based on previous research, one could, for instance, have expected characteristics more central to the stereotype to be more stable (Garcia-Marques et al, 2006). As a proxy of centrality, one could use the pre-migration stereotype mean scores - basic values with more extreme scores could be argued to be more central to the stereotype. But the results did not support the idea that perceptions of more central values (e.g., Security) would have been more stable.

\section{Predicting Stereotype Change at the Level of the Individual}

Regarding consensus, the results of the present research can be summarized as showing that (a) Finns' auto- and migrants' hetero-stereotypes across time showed similar levels of moderate within-group consensus (ICCs ranging from .30 to .62), (b) consensus neither increased nor decreased during the migration process, suggesting a negligible role of increased contact on consensus, and (c) stereotype change during the migration process was not consensual. The last point is particularly important, as it confirms that stereotypes did not change merely as a function of migrants' common experiences with cultural institutions, but rather that stereotypes change was determined also by personal experiences. This is consistent with the low rank-order stabilities of ratings of some of the values, and with the only moderate stability of individual-level profile indices (ICCs ranging from .30 to .48).

Although stereotypes were only moderately stable and changed in different ways across individuals, we were unable to predict such changes: neither positive nor negative contact with native Finns predicted changes in the stereotype of Finns. This was true regarding both changes in the content of the stereotype and overall quantity of change. Furthermore, pre-migration measures of prior contact with Finns, as well as attitudes towards Finns, failed to predict either the initial stereotype of Finns or changes in that stereotype. Consistent with this lack of individual-level results, none of the results obtained in the samples of Ingrian Finn and Russia migrants differed notably. 
For some aspects of the stereotype - i.e. those that showed similar changes across individuals, such as perceptions of Finns' adherence to Tradition - the result that we could not find individual level predictors was not that surprising. However, for other aspects of the stereotype, such as Benevolence values, the fact that neither quantity nor quality of intergroup contact predicted stereotype change can be considered surprising. Such results appear to contradict previous research that has shown cross-group friendships to predict more positive attitudes towards the outgroup (Paolini et al., 2003). One reason that changes in stereotypes were independent of reports of intergroup contact could be that the latter may be highly biased. Such bias may be partly conscious, as the reporting of negative intergroup contact is socially undesirable (Krieger, Smith, Naishadham, Hartman, \& Barbeau, 2005), and this may be particularly true if the outgroup is composed of host nationals whose acceptance migrants may seek. Importantly, a large body of research demonstrates that peoples' memories for events are often distorted and reconstructed in ways incongruent with what actually happened (e.g., Kunda, 1999). For instance, self-enhancement and selfprotection motives (e.g.,Wilson \& Ross, 2003), as well as belongingness and relational needs (e.g., Gardner, Pickett, \& Brewer, 2000; Karney \& Coombs, 2000), may influence memory reconstruction and selective memory biases. Most pertinent to the present research, there is ample evidence that people tend to deny or minimize experiences of discrimination (e.g., Crosby, 1984; Taylor, Wright, Moghaddam, \& Lalonde, 1990), at least in part to protect their self-esteem (e.g., Ruggiero \& Taylor, 1997). However, we acknowledge that a different line of research suggests that attributing negative feedback to prejudice buffers the consequences of such feedback on self-esteem (e.g., Crocker, Voelkl, Testa, \& Major, 1991). However, this latter line of research may be less relevant, as our measure of experienced discrimination explicitly measured discrimination attributable to prejudice, including items such as "I think native Finns do not accept me because I come from Russia”. Both denying direct discrimination due to ethnicity (Ruggiero \& Taylor, 1997), and attributing negative treatment 
with unknown causes to prejudice (Crocker et al., 1991), may therefore serve to protect selfesteem.

Summarizing the above, because judgments of intergroup contact and particularly discrimination are strongly associated with how people perceive and feel about themselves (see also, Dion \& Earn, 1975; Major, Spencer, Schmader, Wolfe, \& Crocker, 1997), such judgements may be based on highly motivated information processing biases. By contrast, judgments of the typical Finn's personal values are likely to be less personally relevant and therefore less suspect to motivational biases. The extent to which migrants' stereotypes of host nationals are associated with reports of intergroup contact should be assessed in other contexts. The associations between migrants' stereotypes and their well-being or adjustment should also be examined. Stereotype judgments could turn out to be a useful, perhaps less motivationally biased, compliment to more traditional measures of intergroup contact.

\section{Conclusions}

Perhaps one of the most basic questions in research on national stereotypes is whether the content of stereotypes is affected by personal contact. In essence, do the impressions that are formed in direct contact with outgroup members generalize to other group members? Or are stereotypes largely independent of direct personal experience? Our results suggest that it depends on the characteristic being assessed. Both in terms of absolute and rank-order stability, ratings of Benevolence were highly malleable, suggesting that actual experience with Finns changed migrants' perceptions. This result thus suggests that the more or less automatic judgements (Abele \& Bruckmüller, 2011) that people make of others' communal characteristics may influence stereotypes.

Regarding perceptions of other characteristics, our results indicate that Finns became increasingly perceived as more conservative. But here, the migrants kept their relative positions, suggesting that differing personal experiences may not have been responsible for these changes in the perception of Finns. Rather, common experiences of Finnish cultural institutions are likely to have caused these changes - in particular, as argued above, we 
believe such shifts in the stereotype of Finns to have been caused by the rise of the True Finns during the time-span of the present research. The present results thus suggest that the mechanisms of stereotype change may be different for different characteristics. Personal contact may influence some aspects of the stereotype, whereas other aspects of the stereotype may be more influenced by common cultural experiences.

Regarding correspondence of migrants' stereotypes with Finns' self-ratings and Finns' auto-stereotype, firm conclusions were difficult to draw. Pre-migration stereotypes were both accurate and similar to auto-stereotypes, and this most likely contributed to their extremely high stability. Studying a sample of migrants whose pre-migration stereotypes were either more inaccurate, or deviated more from host nationals' auto-stereotype, could prove to be illuminating regarding the influence of accuracy and auto-stereotypes on stereotype formation. More generally, perhaps one of the most promising research designs for future research on the mechanisms of national stereotypes could be the longitudinal study of migrants. Many processes are likely to be context specific, but some may generalize across contexts. For instance, we believe that the disillusionment process may be specific to voluntary migration contexts. Even more specifically, the observed changes in the perception of host nationals' adherence to Conservation values may have been solely due to the particular upsurge of one political party. However, some of our results may have more general bearing, such as the result that personal contact may influence some aspects of the stereotype - specifically, those aspects related to communal characteristics - whereas other aspects of the stereotype - perhaps those that are judged less automatically in interpersonal contact - may be more strongly affected by cultural institutions. 


\section{References}

Abele, A. E., \& Bruckmüller, S. (2011). The bigger one of the "Big Two"? Preferential processing of communal information. Journal of Experimental Social Psychology, 47, 935-948.

Abele, A. E., \&Wojciszke, B. (2007). Agency and communion from the perspective of self and others. Journal of Personality and Social Psychology, 93, 751-763.

Allport, G. W. (1978/1954). The nature of prejudice (25th Anniversary ed.). New York: Basic Books.

Arter, D. (2010). The breakthrough of another West European populist radical right party? The case of the True Finns. Government and Opposition, 45, 484-504.

Baumeister, R. F., \& Leary, M. R. (1995). The need to belong: Desire for interpersonal attachments as a fundamental human motivation. Psychological Bulletin, 117, 497529.

Berry, J. W., Phinney, J. S., Sam, D. L., \& Vedder, P. (Eds.). (2006). Immigrant youth in cultural transition: Acculturation, identity and adaptation across national contexts. Mahwah, NJ: Lawrence Erlbaum.

Brigham, J. C. (1971). Ethnic stereotypes. Psychological Bulletin, 76, 15-38.

Chen, M., \& Bargh, J. A. (1997). Nonconscious behavioral confirmation processes: The selffulfilling nature of automatically-activated stereotypes. Journal of Experimental Social Psychology, 33, 541-560.

Conway, M., Pizzamiglio,M. T.,\& Mount, L. (1996). Status, communality and agency: Implications for the stereotypes of gender and other groups. Journal of Personality and Social Psychology, 71, 25-38.

Costa, P. T., Jr., Terracciano, A., \& McCrae, R. R. (2001). Gender differences in personality traits across cultures: Robust and surprising findings. Journal of Personality and Social Psychology, 81, 322-331. 
Church, A. T. (2008). Current controversies in the study of personality across cultures. Social and Personality Psychology Compass, 2, 1930-1951.

Church, A. T., \& Katigbak, M. S. (2002). The Five-Factor Model in the Philippines: Investigating Trait Structure and Levels Across Cultures. In R. R. McCrae \& J. Allik (Eds.): The Five-Factor Model of personality across cultures. Kluwer Academic/Plenum Publishers; New York: 2002. pp. 129-154.

Crocker, J., Voelkl, K., Testa, M., \& Major, B. (1991). Social stigma: The affective consequences of attributional ambiguity. Journal of Personality and Social Psychology, 60, $218-228$.

Cronbach, L. J. (1955). Process affecting scores on "understanding others" and "assumed similarity". Psychological Bulletin, 52, 177-193.

Crosby, F. (1984). The denial of personal discrimination. American Behavioral Scientist, 27, $371-386$.

Davidov, E. (2010). Testing for comparability of human values across countries and time with the third round of the European Social Survey. International Journal of Comparative Sociology, 51, 171-191.

Davidov, E., Schmidt, P., \& Schwartz, S.H. (2008). Bringing values back in: The adequacy of the European Social Survey to measure values in 20 countries. Public Opinion Quarterly, 72, 420-445.

De Cremer, D., \& Van Dijk, E. (2005). When and why leaders put themselves first: Leader behaviour in resource allocations as a function of being entitled. European Journal of Social Psychology, 35, 553-563.

Dion, K. L., \& Earn, B. M. (1975). The phenomenology of being a target of prejudice. Journal of Personality and Social Psychology, 32, 944-950.

Edwards, A.L. (1953). The relationship between the judged desirability of a trait and the probability that the trait will be endorsed. Journal of Applied Psychology, 37, 90-93. 
Fischer, R., \& Schwartz, S. H. (2011). Whence differences in value priorities? Individual, cultural, or artifactual sources. Journal of Cross-Cultural Psychology, 42, 1127-1144.

Garcia-Marques, L., Santos, A. S. C., \& Mackie, D. M. (2006). Stereotypes: Static abstractions or dynamic knowledge structures? Journal of Personality and Social Psychology, 91, 814-831.

Gardner, W. L., Pickett, C. L., \& Brewer, M. B. (2000). Social exclusion and selective memory: How the need to belong influences memory for social events. Personality and Social Psychology Bulletin, 26, 486-496.

Gilbert, G. M. (1951). Stereotype persistence and change among college students. Journal of Abnormal and Social Psychology, 46, 245-254.

Hall, J. A., Coats, E. J., \& LeBeau, L. S. (2005). Nonverbal behaviour and the vertical dimension of social relations: A meta-analysis. Psychological Bulletin, 131, 898-924.

Huddy, L., \& Sears., D. O. (1995). Opposition to bilingual education: Prejudice or the defense of realistic interests? Social Psychology Quarterly, 58, 133-43.

Karlins, M., Coffman, T. L., \& Walters, G. (1969). On the fading of social stereotypes: Studies in three generations of college students. Journal of Personality and Social Psychology, 13, 1-16.

Katz, D., \& Braly, K.W. (1933). Racial stereotypes of one-hundred college students. Journal of Abnormal and Social Psychology, 28, 280-290.

Kraus, M. W., \& Keltner, D. (2009). Signs of socioeconomic status: A thin-slicing approach. Psychological Science, 20, 99-106.

Islam, M. R., \& Hewstone, M. (1993). Dimensions of contact as predictors of intergroup anxiety, perceived out-group variability, and out-group attitude: an integrative model. Personality and Social Psychology Bulletin, 19, 700-710.

Jasinskaja-Lahti, I. \& Mähönen, T. A. (in press). Anticipated and perceived intergroup relations as predictors of immigrants' identification patterns: A longitudinal study. European Psychologist. 
Jasinskaja-Lahti, I., Mähönen, T. A., \& Ketokivi, M. (2012). The dynamics of ethnic discrimination, identities, and outgroup attitudes: A pre-post longitudinal study of ethnic remigrants. Unpublished manuscript.

Jasinskaja-Lahti, I., Mähönen, T. A., \& Liebkind, K. (in press). Identity and attitudinal reactions to perceptions of intergroup contact among ethnic migrants: A longitudinal study. British Journal of Psychology.

Jasinskaja-Lahti, I., \& Yijälä, A. (2011). The model of pre-acculturative stress. A premigration study of potential migrants from Russia to Finland. International Journal of Intercultural Relations, 35, 499-510.

Jowell, R., \& the Central Coordinating Team (2007). European Social Survey 2006/2007: Technical Report. London: Centre for Comparative Social Surveys, City University (2007). The data archive: Norwegian Social Science Data Service (NSD).

Karney, B. R., \& Coombs, R. H. (2000). Memory bias in evaluations of close relationships: Consistency or improvement? Personality and Social Psychology Bulletin, 26, 959970.

Katz, D., \& Schanck, R. L. (1938). Social psychology. New York: Wiley.

Kinder, D. R., Sears, D. O. (1981). Prejudice and politics: Symbolic racism versus racial threats to the good life. Journal of Personality and Social Psychology, 40, 414 31.

Krieger, N., Smith, K., Naishadham, D., Hartman, C., \& Barbeau, E. M. (2005). Experiences of discrimination: Validity and reliability of a self-report measure for population health research on racism and health. Social Science and Medicine, 61, 1576-1596.

Kunda, Z. (1999). Social cognition: Making sense of people. Cambridge, MA: MIT Press.

Kunda, Z., \& Oleson, K. C. (1995). Maintaining stereotypes in the face of disconfirmation: Constructing grounds for subtyping deviants. Journal of Personality and Social Psychology, 68, 565-579. 
Lindeman, M. \& Verkasalo, M. (2005). Measuring values with the Short Schwartz Values Survey. Journal of Personality Assessment, 85, 170-178.

Lord, C., Ross, L., \& Lepper, M. E. (1979). Biased assimilation and attitude polarization: The effects of prior theories on subsequently considered evidence. Journal of Personality and Social Psychology, 37, 2098-2109.

Lönnqvist, J.-E., Yijälä, A., Jasinskaja-Lahti, I., \& Verkasalo, M. (2012). Accuracy and contrast in national value stereotypes - A case study using bi-cultural experts. International Journal of Intergroup Relations, 36, 271-278.

Madon, S., Guyll, M., Aboufadel, K., Montiel, E., Smith, A., Palumbo, P., et al. (2001). Ethnic and national stereotypes: The Princeton trilogy revisited and revised. Personality and Social Psychology Bulletin, 27, 996-1010.

Major, B., Spencer, S., Schmader, T., Wolfe, C., \& Crocker, J. (1997). Coping with negative stereotypes about intellectual performance: The role of psychological disengagement. Personality and Social Psychology Bulletin, 24, 34-50.

Mazzoleni, G., Stewart, J. \& Horsfield, B. (2003). The media and neo-populism: A contemporary comparative analysis. Westport, CT: Praeger.

McCrae, R. R., Kurtz, J. E., Yamagata, S., \& Terracciano, A. (2011). Internal consistency, retest reliability, and their implications for personality scale validity. Personality and Social Psychology Review, 15, 28-50.

McCrae, R. R., Terracciano, A., Realo, A., \& Allik, J. (2007). Climatic warmth and national wealth: Some culture-level determinants of national character stereotypes. European Journal of Personality, 21, 953-976.

Misangyi, V.F., LePine, J.A., Algina, J., \& Goeddeke, F. Jr. (2006). The adequacy of repeated-measures regression for multilevel research. Organizational Research Methods, 9, 5-28. 
Mlicki P, \& Ellemers N. (1996). Being different or being better? National stereotypes and identifications of Polish and Dutch students. European Journal of Social Psychology, $26,97-114$.

Nurmi, H, \& Nurmi, L. (2012). The parliamentary election in Finland, April 2011. Electoral Studies, 31, 234-238.

Paolini, S., Hewstone, M., Cairns, E. \& Voci, A. (2004) Effects of direct and indirect crossgroup friendships on judgements of catholics and protestants in Northern Ireland: The mediating role of an anxiety-reduction Mechanisim. Personality and Social Psychology Bulletin, 30, $770-786$.

Pettigrew, T. F., \& Tropp, L. R. (2006). A meta-analytic test of intergroup contact theory. Journal of Personality and Social Psychology, 90, 751-783.

Phinney, J. S., \& Devich-Navarro, M. (1997). Variations in bicultural identification among African American and Mexican American adolescents. Journal of Research on Adolescence, 7, 3-32.

Realo, A., Allik, J., Lönnqvist, J.-E., Verkasalo, M., Kwiatkowska, A., Kööts, L. et al. (2009). Mechanisms of the national character stereotype: How people in six neighboring countries of Russia describe themselves and the typical Russian. European Journal of Personality, 23, 229 - 249.

Riketta, M. (2005). Cognitive differentiation between self, ingroup, and outgroup: The roles of identification and perceived intergroup conflict. European Journal of Social Psychology, 35, 97-106.

Robins, R. W. (2005). The nature of personality: Genes, culture, and national character. Science, 310, 62-63.

Rokeach, M. (1973). The nature of human values. New York: Free Press.

Rothbart, M., \& John, O. P. (1993). Intergroup relations and stereotype change: A socialcognitive analysis and some longitudinal findings. In P. M. Sniderman, P. E. Tetlock, \& E. G. Carmines (Eds.), Prejudice, politics and the American dilemma (pp. 32-59). 
Stanford, CA: Stanford University Press.

Schoenfeld, N. (1942). An experimental study of some problems relating to stereotypes. Archives of Psychology, No. 270.

Schwartz, S. H. (1992). Universals in the content and structure of values: Theoretical advances and empirical tests in 20 countries. In Zanna, M. (Ed.), Advances in experimental social psychology, 25, 1-65. New York: Academic Press.

Schwartz, S. H. (1994). Beyond individualism-collectivism: New cultural dimensions of values. In U. Kim, H. C. Triandis, Ç. Kagitçibasi, S.-C. Choi, \& G. Yoon (Eds.), Individualism and collectivism: Theory, method, and applications (pp. 85-119). Thousand Oaks, CA: Sage.

Schwartz, S. H. (2007). Value orientations: Measurement, antecedents and consequences across nations. In R. Jowell, C. Roberts, R. Fitzgerald, \& G. Eva (Eds.), Measuring attitudes cross-nationally: Lessons from the European Social Survey (pp. 161-193). London: Sage.

Schwartz, S. H. (2008) Cultural value orientations: Nature and implications of national differences. Moscow: State University-Higher School of Economics Press.

Schwartz, S. H. (2009). Culture matters: National value cultures, sources and consequences. In C.-Y. Chiu, Y.Y. Hong, S. Shavitt, \& R. S. Wyer, Jr. (Eds.), Understanding culture: Theory, research and application. New York: Psychology Press.

Schwartz, S. H., \& Bardi, A. (2001). Value hierarchies across cultures: Taking a similarities perspective. Journal of Cross-Cultural Psychology, 32, 268-290.

Schwartz, S. H., \& Rubel, T. (2005). Sex differences in value priorities: Cross-cultural and multimethod studies. Journal of Personality and Social Psychology, 89, 1010-1028.

Tartakovsky, E. (2009a). Cultural identities of adolescent immigrants: A three year longitudinal study including the pre-migration period. Journal of Youth and Adolescence, 38, 654-671.

Tartakovsky, E. (2009b). The psychological well-being of unaccompanied minors: A 
longitudinal study of adolescents immigrating from Russia and Ukraine to Israel without parents. Journal of Research on Adolescence, 19, 177-204.

Taylor, D. M., Wright, S. C., Moghaddam, F. M., \& Lalonde, R. N. (1990). The personal/group discrimination discrepancy: Perceiving my group, but not myself, to be a target of discrimination. Personality and Social Psychology Bulletin, 16, 254262.

Tellegen, A. (1965). Direction of measurement: A source of misinterpretation. Psychological Bulletin, 63, 233-243.

Terracciano, A., Abdel-Khalek, A. M., Adam, N., Adamovova, L., Ahn, C., Ahn, H. N., et al. (2005). National character does not reflect mean personality trait levels in 49 cultures. Science, 310, 96-100.

Terracciano, A., \& McCrae, R. R. (2007). Perceptions of American and the Iraq Invasion: Implications for understanding national character stereotypes. Journal of CrossCultural Psychology, 38, 695-710.

Tropp, L. R. (2003). The psychological impact of prejudice: Implications for intergroup contact. Group Processes and Intergroup Relations, 6, 131-149.

Verkuyten, M. (2007). Religious group identification and inter-religious relations: A study among Turkish-Dutch Muslims. Group Processes and Intergroup Relations, 10, 341 357.

Voci, A., \& Hewstone, M. (2003). Intergroup contact and prejudice toward immigrants in Italy: The mediational role of anxiety and the moderational role of group salience. Group Processes and Intergroup Relations, 6, 37-54.

Wilson, A. E., \& Ross, M. (2003). The identity function of autobiographical memory: Time is on our side. Memory, 11, 137-149.

Yijälä, A. \& Jasinskaja-Lahti, I. (2010). Pre-migration acculturation attitudes among potential ethnic migrants from Russia to Finland. International Journal of Intercultural Relations, 34, 326-339. 
Group-Level and Intraindividual Stability 37

Zook, D. C. (2009). The curious case of Finland's clean politics. Journal of Democracy, 20, $157-168$ 
Table 1. Means and Standard Deviations of Finns' Personal Values and Finns', Ingrian Finns', and Russians Stereotypes of Finns' Personal Values.

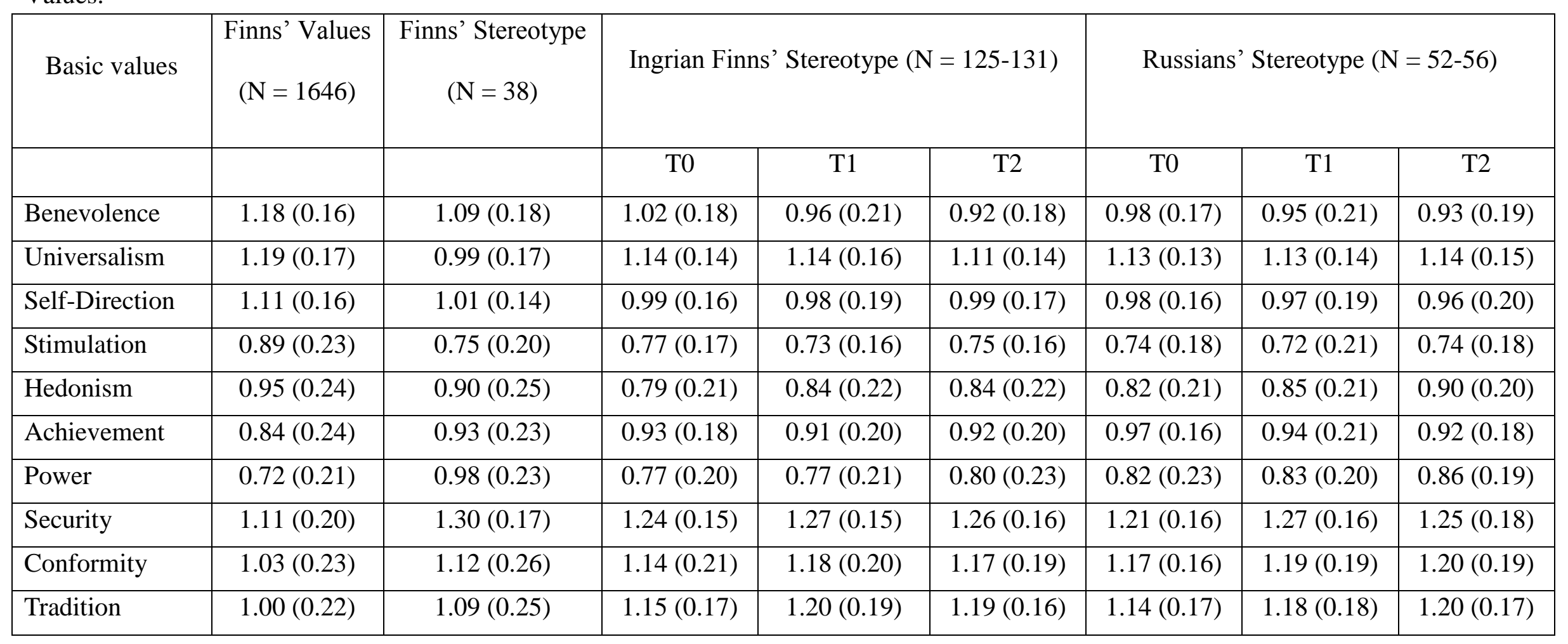


Table 2. Intra-Class Correlation Coefficients for Stereotype Ratings.

\begin{tabular}{|c|l|l|}
\hline & Single measures ICC & Average measures ICC \\
\hline Finns' Stereotype & $.32(.17-.62)$ & $.95(.89-.98)$ \\
\hline Ingrian Finns' Stereotype & & \\
\hline T0 & $.51(.33-.78)$ & $.99(.98-1.00)$ \\
\hline $\mathrm{T} 1$ & $.50(.32-.77)$ & $.99(.98-1.00)$ \\
\hline $\mathrm{T} 2$ & $.47(.29-.75)$ & $.99(.97-1.00)$ \\
\hline Russians' Stereotype & & \\
\hline $\mathrm{T} 0$ & $.39(.22-.71)$ & $.97(.94-.99)$ \\
\hline $\mathrm{T} 1$ & $.39(.22-.71)$ & $.97(.94-.99)$ \\
\hline $\mathrm{T} 2$ & $.62(.33-.97)$ & $.99(.96-1.00)$ \\
\hline
\end{tabular}

Note. The numbers in parenthesis are $95 \%$ confidence intervals. 
Group-Level and Intraindividual Stability 40

Table 3. Group-Level Profile Similarity Coefficients between Finns' Personal Values and Finns', Ingrian Finns', and Russians' Stereotype of Finns' Values.

\begin{tabular}{|c|c|c|c|c|c|c|c|c|}
\hline & \multirow{2}{*}{$\begin{array}{c}\text { Finns' Values } \\
\qquad(\mathrm{N}=1646) \\
1 .\end{array}$} & \multirow{2}{*}{$\begin{array}{l}\text { Finns' Stereotype } \\
\qquad(\mathrm{N}=38) \\
2 .\end{array}$} & \multicolumn{3}{|c|}{$\begin{array}{c}\text { Ingrian Finns' } \\
\text { Stereotype }(N=125)\end{array}$} & \multicolumn{3}{|c|}{$\begin{array}{c}\text { Russians' Stereotype } \\
(N=52)\end{array}$} \\
\hline & & & 3. T0 & 4. $\mathrm{T} 1$ & 5. T2 & 6. T0 & 7. $\mathrm{T} 1$ & 8. T2 \\
\hline 1. & & & & & & & & \\
\hline 2. & .49 & & & & & & & \\
\hline 3. & $.71^{*}$ & $.83^{*}$ & & & & & & \\
\hline 4. & $.64 *$ & $.83^{*}$ & $.98 *$ & & & & & \\
\hline 5. & .58 & $.83^{*}$ & $.97 *$ & $1.00 *$ & & & & \\
\hline 6. & .62 & $.83 *$ & $.98 *$ & $.99 *$ & $.98^{*}$ & & & \\
\hline 7. & .57 & $.86^{*}$ & .97 & $.99 *$ & $.99 *$ & ,99* & & \\
\hline 8. & .54 & $.83^{*}$ & $.94 *$ & $.98 *$ & $.99 *$ & $.97 *$ & $.99 *$ & \\
\hline
\end{tabular}

Note. $* p<.05$ 
Table 4. Change in Stereotypes: Means, Standard Deviations, and Range of Regression Estimates from Within-Individual Analyses

\begin{tabular}{|c|c|c|c|c|c|c|c|c|}
\hline \multirow[t]{2}{*}{ Basic values } & \multicolumn{4}{|c|}{ Ingrian Finns' Stereotype $(\mathrm{N}=120)$} & \multicolumn{4}{|c|}{ Russians' Stereotype $(\mathrm{N}=53)$} \\
\hline & Intercept & Beta & Beta range & Beta $^{2}$ & Intercept & Beta & Beta range & Beta $^{2}$ \\
\hline & $\mathrm{M}(\mathrm{SD})$ & $\mathrm{M}(\mathrm{SD})$ & Beta $_{\min }-$ Beta $_{\max }$ & $\mathrm{M}(\mathrm{SD})$ & $\mathrm{M}(\mathrm{SD})$ & $\mathrm{M}(\mathrm{SD})$ & Beta $_{\min }-$ Beta $_{\max }$ & $\mathrm{M}(\mathrm{SD})$ \\
\hline Benevolence & $1.01(0.18)$ & $-0.11(0.58)^{*}$ & $-1.60-1.49$ & $0.02(0.24)$ & $0.98(0.17)$ & $-0.05(0.51)$ & $-1.50-1.41$ & $0.02(0.22)$ \\
\hline Universalism & $1.14(0.14)$ & $0.00(0.43)$ & $-1.93-1.16$ & $-0.01(0.19)$ & $1.14(0.13)$ & $-0.01(0.38)$ & $-1.13-0.90$ & $0.01(0.15)$ \\
\hline Self-Direction & $0.99(.17)$ & $0.00(0.49)$ & $-1.30-2.24$ & $0.01(0.21)$ & $0.98(0.16)$ & $-0.02(0.43)$ & $-1.32-0.79$ & $0.01(0.15)$ \\
\hline Stimulation & $0.78(0.17)$ & $-0.14(0.55)^{*}$ & $-2.95-1.44$ & $0.06(0.24)^{*}$ & $0.74(0.18)$ & $-0.04(0.42)$ & $-1.22-1.25$ & $0.01(0.16)$ \\
\hline Hedonism & $0.79(0.21)$ & $0.11(0.58)^{*}$ & $-1.44-2.65$ & $-0.04(0.26)$ & $0.82(0.21)$ & $0.04(0.49)$ & $-1.11-1.74$ & $-0.01(0.20)$ \\
\hline Achievement & $0.94(0.18)$ & $-0.04(0.51)$ & $-1.89-1.65$ & $0.01(0.22)$ & $0.97(0.16)$ & $-0.05(0.49)$ & $-1.64-1.31$ & $0.01(0.20)$ \\
\hline Power & $0.77(0.21)$ & $-0.03(0.54)$ & $-1.23-2.22$ & $0.02(0.22)$ & $0.82(0.23)$ & $-0.02(0.54)$ & $-1.46-1.11$ & $0.02(0.20)$ \\
\hline Security & $1.24(0.15)$ & $0.10(0.45)^{*}$ & $-0.95-2.79$ & $-0.04(0.20)$ & $1.22(0.16)$ & $0.10(0.31)^{*}$ & $-0.47-1.15$ & $-0.03(0.13)$ \\
\hline Conformity & $1.15(0.21)$ & $0.06(0.60)$ & $-1.58-2.88$ & $-0.03(0.27)$ & $1.18(0.16)$ & $0.00(0.61)$ & $-2.43-1.22$ & $0.02(0.30)$ \\
\hline Tradition & $1.16(0.17)$ & $0.10(0.55)^{*}$ & $-1.76-2.88$ & $-0.04(0.26)$ & $1.14(0.17)$ & $0.07(0.39)$ & $-0.89-1.15$ & $-0.01(0.15)$ \\
\hline
\end{tabular}

Note. $* p<.05$; one-sample t-test against zero. 
Table 5. Average Individual-Level Profile Similarity Coefficients (Pearson r's) over Time for Ingrian Finns' and Russians' Stereotypes of Finns' Personal Values.

\begin{tabular}{|c|c|c|c|c|}
\hline & \multicolumn{2}{|c|}{ Ingrian Finns $(N=125)$} & \multicolumn{2}{c|}{ Russians $(N=52)$} \\
\hline Time period & Overall & Distinctive & Overall & Distinctive \\
\hline T0 to T1 & .75 & .37 & .74 & .44 \\
\hline T1 to T2 & .77 & .48 & .72 & .42 \\
\hline T0 to T2 & .70 & .31 & .65 & .30 \\
\hline
\end{tabular}

Note. All significant at $p<.001$; one-sample t-test against zero. 
Table 6. Rank-order correlation coefficients for Ingrian Finns' and Russians Stereotypes of Finns' Personal Values.

\begin{tabular}{|l|c|c|c|c|c|c|}
\hline Basic values & \multicolumn{3}{|c|}{ Ingrian Finns $(N=125-131)$} & \multicolumn{3}{c|}{ Russians $(N=52-56)$} \\
\hline & T0 to T1 & T1 to T2 & T0 to T2 & T0 to T1 & T1 to T2 & T0 to T2 \\
\hline Benevolence & .36 & .31 & .05 & .38 & .08 & .33 \\
\hline Universalism & .35 & .48 & .25 & .37 & .48 & .22 \\
\hline Self- & .40 & .49 & .38 & .40 & .48 & .19 \\
\hline Stimulation & .32 & .46 & .43 & .54 & .64 & .56 \\
\hline Hedonism & .53 & .42 & .31 & .42 & .32 & .17 \\
\hline Achievement & .47 & .59 & .32 & .33 & .39 & .29 \\
\hline Power & .43 & .55 & .39 & .29 & .49 & .54 \\
\hline Security & .39 & .42 & .23 & .59 & .52 & .35 \\
\hline Conformism & .31 & .45 & .39 & .37 & .28 & .35 \\
\hline Tradition & .33 & .38 & .26 & .42 & .56 & .32 \\
\hline Average & .39 & .46 & .30 & .42 & .44 & .34 \\
\hline
\end{tabular}

Note. For Ingrian Finns (Russians), all correlations $r \geq .23(r \geq .28)$ are statistically significant at $p<.05$. 